\section{Discrimination, stigma, and AIDS: a review of academic literature produced in Brazil (2005-2010)}

\author{
Discriminação, estigma e AIDS: revisão da \\ produção acadêmica nacional (2005-2010)
}

\author{
Simone Monteiro 1 \\ Wilza Vieira Villela ${ }^{2}$ \\ Daniela Knauth 3
}

\footnotetext{
1 Instituto Oswaldo Cruz, Fundação Oswaldo Cruz, Rio de Janeiro, Brasil. 2 Universidade Federal de São Paulo, São Paulo, Brasil. 3 Faculdade de Medicina, Universidade Federal do Rio Grande do Sul, Porto Alegre, Brasil.

Correspondence

S. Monteiro

Laboratório de Educação em Ambiente e Saúde, Instituto

Oswaldo Cruz, Fundação

Oswaldo Cruz.

Av. Brasil 4365, Sala 22,

Rio de Janeiro, $R J$

21045-900, Brasil.

msimone@ioc.fiocruz.br
}

\begin{abstract}
Given the implications of stigma for HIVIAIDS prevention and control of the epidemic, as emphasized by UNAIDS, this study analyzes the Brazilian academic production on health, AIDS, stigma, and discrimination, available in the SciELO database from 2005 to 2010. Brazilian research on the theme is modest as compared to the international literature, but the studies follow the same trend of focusing on individual experiences of discrimination as opposed to analysis of stigma and discrimination as social processes associated with power relations and domination (macro-social structures) and the characteristics of individuals and social groups that shape social interactions. The current study seeks to analyze the reasons for the scarcity of studies on the social perspective towards stigma and discrimination in the field of public health and the implications for the development of proposals to deal with HIVIAIDS-related discrimination.
\end{abstract}

Social Stigma; Prejudice; Sexually Transmitted Diseases; Acquired Immunodeficiency Syndrome
Three decades since the beginning of the HIV/ AIDS epidemic, significant advances have been made in characterization of the virus, therapy, critique of the risk group concept, attitudes of solidarity, safeguards for the rights of persons living with HIV/AIDS, and the development of actions in prevention and care. Still, AIDS-related stigma and discrimination remain, backed by representations that associate negative moral attributes with carriers of the virus, with implications for prevention and control of the epidemic ${ }^{1}$.

This study aims to analyze the Brazilian academic literature on AIDS, stigma, and discrimination available in the SciELO database from 2005 to 2010, with the purpose of encouraging the development of research and policies on the theme in the public health field in Brazil. The review's premise is that since processes of discrimination and stigma result from social interactions and structures, they stem from the linkage between axis of inequalities, such as social class, gender, generation, and color/race/ethnicity and individual characteristics. Thus, the analysis of these health-related processes should consider the specific interrelations between macro- and micro-social structures in the production of exclusionary mechanisms towards certain individuals and groups, thereby making them more vulnerable 2,3 . 


\section{Methodological procedure}

The review work included searching, classifying, and analyzing the articles. The search was conducted based on integrated and global research, with all the indices, in the SciELO base, for the period from 2005 to 2010 , with the combined use of the descriptors from the Virtual Health Library (BVS) and the subject indices in SciELO, namely: Stigma; Discrimination; HIV; AIDS; Health; AIDS Stigma; Concept; Gender; Sexual Orientation; Social Class; Law; Stigmatization; Color Prejudice; Prejudice and Discrimination; Racial Prejudice; Racial Discrimination; Social Discrimination; and Discrimination Based on Sexual Orientation.

The expanded version of the descriptors beyond the words stigma, discrimination, HIV, and AIDS - aimed at more extensively exploring the topics and approaches pertaining to stigma and discrimination in the Brazilian literature. This approach was defined on the basis of previous studies concerning the relative scarcity of research on the theme in Brazil, in contrast with the international literature.

For purposes of comparison, the same search script used in SciELO was applied to the LILACS database, including the descriptor Brazil. A total of 203 articles were identified, of which only 45 were common to the search done in SciELO, but classification of the articles indicated similar trends, discussed below. Such indications suggest that the above-mentioned databases may be complementary.

Of the 226 articles found in SciELO, we excluded book synopses and thesis abstracts, texts from the field of biology, studies on discrimination as sensory stimuli, articles that only touched on the issue tangentially, and studies conducted outside of Brazil. A total of 163 articles were finally selected. This sample was classified according to the following categories: year of publication; name of the periodical; central theme of the study; population group investigated; methodological approach; analytical focus on discrimination, namely: individual experiences; socio-symbolic dimension; theoretical-conceptual dimension; measures; responses. The data pertaining to classification were entered into Excel (Microsoft Corp., USA) and later transferred to Epi Info (Centers for Disease Control and Prevention, Atlanta, USA) in order to generate frequency tables and allow cross-analysis among the categories.

The construction of categories on stigma and discrimination was based on reading the selected articles, adapted to the reflections on the international literature on the theme, highlighting the importance of relations between culture, power, difference, and social inequalities for understanding the processes of stigma and discrimination $2,3,4$. That is, it is necessary to understand the way by which these vectors (linked in specific ways) influence living conditions and the perceptions of individuals and social groups in relation to the situations associated with stigma and discrimination.

\section{Results}

The Brazilian research output on this theme was limited but evenly distributed during the years covered here (2005: 19 articles; 2006: 24; 2007: 37; 2008: 25; 2009: 32; and 2010: 26) and was spread across 68 periodicals, predominantly in journals in the areas of public health and mental health.

As for the themes, the articles were predominantly on color/race/ethnicity or STD/AIDS, followed by those on discrimination related to health problems. Two other thematic blocs consisted of articles that discussed sexuality, gender, and those that linked more than one social axis of inequality. Users of health services or teaching institutions were the most widely covered population groups, followed by specific populations, persons living with HIV/AIDS, and health workers. Studies focusing on the general population, LGBT groups (lesbians, gays, bisexuals, and transvestites), and users of nongovernmental organizations formed the minority.

The methodological approaches showed a prevalence of qualitative procedures and conceptual studies focused on document analysis and literature reviews. Only eight studies combined qualitative and quantitative methodologies. The most frequent analytical focus on discrimination referred to individual experiences, followed by studies on responses, socio-symbolic dimensions, measures, and theoretical and conceptual approaches.

Of the 33 articles on STD/AIDS, 25 focused on aspects related directly to HIV, and eight analyzed the empirical data based on gender inequalities. There was a concentration of studies on individual experiences of discrimination (22 articles) with the use of qualitative procedures, with an emphasis on persons living with HIV/ AIDS. The articles on responses and measures of discrimination related to STD/AIDS also focused primarily on persons living with HIV/ AIDS. These results suggest the greater visibility of experiences of persons living with HIV/AIDS and are consistent with findings in international reviews 3,4 .

The articles that associated discrimination with other health problems, such as mental dis- 
orders, Hansen's disease, and tuberculosis, confirmed the tendency towards an individual focus in research on stigma in the health field. In such research, illness is seen as a natural and individual event, scarcely linked to social, political, or economic factors that determine its occurrence and the way it is experienced. Critically analyzing the studies on stigma in the field of international health research, and contrasting with the perspective of understanding this process from the dimension of individual experience, studies highlight that stigmatization results from an exercise of power and that these processes have implications for the distribution of life opportunities 2 . This focus allows the understanding of HIV/ AIDS-related stigma in relation to the concept of structural violence, allowing the definition of strategic policy interventions for overcoming it, which does not occur when one operates only within the dimension of individual experience 3 .

One can infer that the large number of articles on color/race/ethnicity results from the visibility gained by the racial relations issue in recent years, combined with discussions on poverty, social justice, and human rights. The analysis of racial inequalities has been used as a tool for understanding the structural mechanisms in the production of iniquities and as a political instrument for overcoming them 5 .

Consistent with this perspective, of the 33 studies identified in the review, half $(51.5 \%)$ referred to responses for dealing with stigma and racial discrimination, with a predominance of studies on the implementation of racial quotas in public universities in Brazil, and also including training on racial relations at different educational levels. There were also significant studies based on documents and literature reviews concerning the historical, socio-cultural, and political/institutional context for social and racial inequalities in the country.

In the field of health, there were fewer studies on color/race/ethnicity. Three articles discussed the implications of ethnic/racial inequalities in health problems and two analyzed the effects of racism on care for health services users. Only one analyzed the policy for the Black population's health, while one other discussed health policies for the indigenous population, suggesting less underlying politicization in the academic output on indigenous peoples in Brazil. Importantly, lack of use of the descriptor "ethnicity" in the search process may have been a factor in the apparent lack of studies on indigenous peoples.

The gender category included articles that dealt with discrimination against women or men based on gender stereotypes or ideologies, and did not consider articles that simply took women as research subjects. Gender studies were classified in three thematic areas: STD/AIDS, work, and the law. Of the eight articles on STD/AIDS and gender, five focused on persons living with HIV/ AIDS, of which four were on women, focusing on maternity issues. This reflects the tradition of health research that considers women primarily in their childbearing role 6 . Meanwhile, the only article on men dealt with issues of HIV/AIDS and employment. The three articles on gender and law took a theoretical perspective, without a clear link to the field of health or other fields of social practices. On the item of gender and work, there was an emphasis on the search for estimates of discrimination against women at the workplace.

Twelve articles discussed sexual orientation as the catalyst for discriminatory practices, focusing mainly on the LGBT population. The studies emphasized the perspective of rights in this group, based on the affirmation of their identities, i.e., without aiming to discuss or confront stigma through denial of the purported difference, but seeking to overcome it by affirmation of the right to otherness.

Among the 11 articles that analyzed the interaction between two or more social axis in producing processes of discrimination, the main target groups were black women and young black men in peripheral urban areas. From this perspective, the studies sought to link inequalities based on gender, class, and race/ethnicity and map their intersections with the attempt to deconstruct them and raise the possibility of redefining them 7 . Unlike the articles that predominantly analyzed individual experiences, the authors tended to focus on the socio-symbolic dimensions of discrimination, in an attempt to approach the structural determinants of its production.

\section{Discussion}

Most of the studies identified in the field of health appear to relate to the concept of stigma, coined by Goffman 8, where the central idea is that of a marked body, rather than a dynamic social process that reproduces itself with a certain level of autonomy in relation to individual subjects. This appropriation of Goffman's concept is similar to the models that explain diseases based on the biological body and individual behaviors. As suggested by Foucaultian thinking, the vocation of biomedicine (as a field of practices and production of truths) is to incorporate, from the perspective of "disease or deviation", whatever is considered socially undesirable, dysfunctional, or divergent. 
The relationship between stigma and a subject's attribute in health studies focused on symbolically marked diseases (e.g., mental disorders, tuberculosis, leprosy), and the concentration of studies that report on individual experiences, reaffirm the perception that discrimination based on stigma results from the interaction between subjects. Thus, the report of an experience can be understood as a means to overcome discrimination through two mechanisms: first by identification, then by differentiation. From this perspective, one person's identification with another and with his or her suffering occurs because both belong to the category of human beings. Differentiation, in turn, results from the perception that only one of the poles in the relationship possesses the mark that gives rise to the discrimination. In this interplay, the mark of the stigma is preserved as a contingent and natural fact. Stated differently, the description of the stigma's effects on subjects, rather than the analysis of the processes involved in its (re)production, is incapable of leveraging political responses through its deconstruction, although it may be useful in exhorting subjects to establish more inclusive relations 9 .

It is important to acknowledge the contributions to the health field by the concept of stigma, as originally formulated by Goffman 10 , but it is necessary to identify the limits of its use in subsequent studies. Such questioning aims to situate stigma and discrimination within the set of social processes in the production of inequalities and to reveal the challenges in the analysis of the tensions and feedback between individual behaviors and collective practices. The assumption that stigma generates prejudice and that the latter spawns discrimination presupposes the origin of processes of discrimination in stigma, overlooking that stigma can be produced through social processes of production of inequalities, in which discrimination and social exclusion are key elements 3,11 .

The contrast between articles on stigma and health, centered on subjects' experiences, and those approaching the racial issue, written from the prism of confrontation (based on racial quotas in schools) or as the result of social inequalities, with little emphasis on health issues, confirms that stigma and discrimination are treated distinctly, regardless of whether they deal with a phenomenon seen as natural or as cultural and political 11 .

The partiality of Brazilian research on stigma and discrimination in relation to AIDS may point to one of the possible effects of HIV/AIDS-related stigma. AIDS has updated the idea of illness as stigma, as with leprosy in pre-Christian times, madness in the Middle Ages, and tuberculosis in the early $20^{\text {th }}$ century 12 . Surprisingly, AIDS has not been approached as a prime object for explaining the social processes and mechanisms that produce and maintain hierarchies, discrimination, and social inequalities.

One possible explanation for this gap is the identification of AIDS and the stigma associated with it as a predominantly political rather than academic issue. A more in-depth analysis of stigmatization and discrimination involves taking a political stance, which could be feared in academia, since it would allow challenging the scientificity of the research itself. In both social and academic terms, the perspective of suffering and its material expression in the body and in illness are more widely accepted than the sociological perspective, seen as militant and scarcely academic. In other words, the absence of academic output on AIDS and stigma in the Brazilian context may signal a demarcation between science and activism, between the scientific and the political.

Importantly, the AIDS epidemic has spawned sociological and anthropological research on the various forms of affective-sexual relations, sexual diversity, drug use, and practices from traditional medicine in African countries. Still, the presence of the social sciences - the theoretical locus of the concepts of stigma, discrimination, inequality, and exclusion, among others - in the research output on themes associated with the HIV/AIDS epidemic has diminished following advances in clinical research and the discovery of new drugs, which have imposed a medical perspective towards the disease 13. Critical analyses of the power relations involved in the epidemic, including stigma and discrimination, in the production of vulnerabilities, tend to become less valued; meanwhile, studies on risk perceptions and behaviors in specific groups, and particularly on treatment adherence, are welcomed.

Another hypothesis for the scarcity of studies on AIDS and stigma in the literature involves the relations between the social movement and government institutions. The active presence of organized civil society in setting the course for AIDS policy in Brazil is a central element in this policy's "success". However, this active stance, combined with the way nongovernmental organizations were funded in the 1990s 14, weakened the role of social control. Some demands by the social movement, when incorporated by public policies, have not been evaluated in terms of their quality, even when they fail to demonstrate a decrease in stigma, discrimination, and social inequalities. There appears to be a fear that analysis of mechanisms that produce and reproduce stigmatizing situations and conditions means 
questioning what are considered "politically correct" government actions. This point can be illustrated by the lack of mechanisms for monitoring and evaluating government-funded preventive activities implemented by civil society organizations. An example is the interventions conducted by NGOs with truck drivers, which largely ignore the local organizational structures and produce actions with little impact on this group's level of knowledge or preventive practices 15.

Likewise, even with the increase in the number of AIDS cases among women, the epidemic in Brazil is predominantly male, with greater than $5 \%$ prevalence among men who have sex with men and male injecting drug users 16. Still, the link between AIDS and homophobia in the production or reiteration of stigma has not become a topic of major academic interest. The same can be said of drug users or transvestites, groups affected by HIV/AIDS which in some way correspond to the Goffmanian concept of "bodily mark", but which have not been targeted in reflections on stigma and health. This absence contrasts with the strong presence of women, approached thematically through their social identity as mothers, suggesting the reproduction of stigmatization and gender stereotyping in the area of academic studies 6 .

\section{Final remarks}

Analysis of the research output on stigma, discrimination, and AIDS shows elements that allow a better understanding of the dominant representations concerning these issues in the Brazilian scientific field. Few studies have focused on the social processes that generate stigma and discrimination, while studies have tended to focus more on the individual experiences of specific social segments.

Stigma is investigated in social groups that are previously assumed to be carriers of stigma and targets of discrimination. The point of departure is bodies marked by a given condition or situation - a specific disease, life phase, gender - in order to show the individual experiences or dominant concepts in given spaces and institutions concerning these bodies. The question is what this says about the processes of stigma and discrimination in Brazilian society.

The focus of Brazilian research on the theme in the health field also appears to reveal another side of the hegemonic conceptualization of discrimination, namely its direct association with suffering as a category. The materialization of stigma in given bodies and the suffering it produces relates this problem to the health field, and particularly that of mental health, a specialty prepared to detect and "treat" suffering. The perspective of suffering is crucial for understanding stigma and discrimination as processes that allude to the individual dimension of subsequent interventions, in which the stigmatized are viewed as victims and those that practice stigmatizing are seen as guilty. If there are victims and guilty parties, the question is perceived again as individual, circumscribed within given contexts or institutions, where the interventions are expected to diminish the victim's suffering based on the correction of the guilty parties' behaviors, prioritizing information and aware-raising strategies concerning the other person's suffering.

Meanwhile, the social studies of science indicate that scientific narratives, by proposing a description of natural and social phenomena, contribute to the construction of these very phenomena and the way society grasps them. Science, produced by individuals, finds itself immersed in society, whose dominant values and ideas it shares, thereby producing a narrative which, although presented as scientific, neutral, and unique, is actually partial and localized. One can thus contend that the way the production of scientific knowledge grasps stigma and discrimination somehow reflects the hegemonic way in which Brazilian society perceives and determines its actions towards this issue.

The feedback between science and society towards processes of stigma and discrimination can be analyzed from the perspective of the idea of racial democracy, for example. This concept was coined in a complex process of scientific production and ideas that were current at the time (during the Imperial Period), and referred to the slaveholding system in Brazil, purportedly more "humane" than elsewhere. Beginning in the 1930s, the term gained importance in academic debates, in a process in which an idea that originally emerged in slaveholding society entered the intellectual milieu, which provided scientific evidence and explanations for the idea, which subsequently came to be taken for granted 17,18,19.

Thus, the scarcity of scientific production on stigma and discrimination, although not referring specifically to studies on racial relations, somehow relates to this mythology on the absence of prejudices in Brazil. It is also in this sense that discrimination can be perceived as the result of an individual interaction, related to private attitudes and lack of information, and where the hierarchies, inequalities, and power relations that produce stigma and discrimination fail to appear.

Despite the limits of the time period and scope of the Brazilian national review performed 
here, the article's findings reveal similar trends to those of the international literature, while also identifying specificities in the Brazilian context. The results suggest the need for (and relevance of) encouraging the development of new conceptual and methodological contributions, capable of contemplating the analysis of social and cultural norms and relations of power and oppression in the Brazilian research output on stigma and discrimination (AIDS-related in particular and health-related in general). Importantly, the gaps in research on structural aspects referring to the political, economic, and social aspects that produce stigma and discrimination have significant impacts on the design of responses to stigma and discrimination, associated not only with the HIV/AIDS epidemic, but also with other health problems in the Brazilian context.

\section{Resumo}

Frente às implicações do estigma para a prevenção $e$ o controle da epidemia de HIVIAIDS, destacada pela UNAIDS, este trabalho analisa a produção acadêmica nacional sobre saúde, AIDS, estigma e discriminação, disponível no SciELO, de 2005 a 2010. Constatou-se que a literatura sobre o tema não é expressiva, quando comparada à literatura internacional; no entanto, os trabalhos seguem a mesma tendência de privilegiar as experiências individuais de discriminação, em detrimento da análise do estigma e da discriminação como processos sociais, associados às relações de poder e dominação (estruturas macrossociais), assim como às características dos indivíduos e grupos sociais que conformam as interações sociais. O trabalho busca analisar as razões para a escassez de estudos sobre a perspectiva social do estigma e da discriminação no campo da saúde pública, e suas implicações para o desenvolvimento de propostas de enfrentamento da discriminação associada ao HIVIAIDS.

Estigma Social; Preconceito; Doenças Sexualmente Transmissiveis; Síndrome de Imunodeficiência Adquirida

\section{Contributors}

S. Monteiro and W. V. Villela participated in conceiving and writing the article. D. Knauth contributed with discussion of the results and helped revise the article.

\section{Acknowledgments}

The authors wish to thank FAPERJ for its support as well as Carla Pereira and Priscila Soares for their collaboration in the review work. 


\section{References}

1. Joint United Nations Programme on HIV/AIDS. Report on the Global AIDS Epidemic 2010. Geneva: Joint United Nations Programme on HIV/AIDS; 2010.

2. Link B, Phelan J. Conceptualizing stigma. Annu Rev Sociol 2001; 27:363-85.

3. Parker R, Aggleton P. HIV and AIDS related stigma and discrimination: a conceptual framework and implications for action. Soc Sci Med 2003; 57:13-24.

4. Mahajan AP, Sayles JN, Patel VA, Remien RH, Sawires S, Ortiz D, et al. Stigma in the HIV/AIDS epidemic: a review of the literature and recommendations for the way forward. AIDS 2008; 22 Suppl 2:S67-79.

5. Htun M. From "racial democracy" to affirmative action: changing state policy on race in Brazil. Latin American Research Review 2004; 39:60-89.

6. Villela W, Monteiro S, Vargas E. A incorporação de novos temas e saberes nos estudos em saúde coletiva: o caso do uso da categoria gênero. Ciênc Saúde Coletiva 2009; 14:997-1006.

7. Monteiro S, Cecchetto F. Cor, gênero e classe: dinâmicas da discriminação entre jovens de grupos populares cariocas. Cadernos Pagu 2009; 32:301-30.

8. Goffman E. Estigma. Notas sobre a manipulação da identidade deteriorada. Rio de Janeiro: Editora Zahar; 1980.

9. Finn M, Srikant S. Humanizing HIV/AIDS and its (re)stigmatizing effects: HIV public 'positive' speaking in India. Health 2009; 13:47-65.

10. Nunes E. Goffman: contribuições para a Sociologia da Saúde. Physis (Rio J.) 2009; 19:173-87.
11. Phelan J, Link B, Dovidio JF. Stigma and prejudice: one animal or two? Soc Sci Med 2008; 67:358-67.

12. Sontag S. A doença como metáfora. Rio de Janeiro: Edições Graal; 1984.

13. Guimarães CD. Aids no feminino. Por que a cada dia mais mulheres contraem Aids no Brasil? Rio de Janeiro: Editora UFRJ; 2001.

14. Galvão J. Aids no Brasil. São Paulo: Editora 34; 2000.

15. Leal AF. No peito e na raça. A construção da vulnerabilidade de caminhoneiros: um estudo antropológico de políticas públicas para HIV-AIDS no Sul do Brasil [PhD Dissertation]. Porto Alegre: Universidade Federal Rio Grande do Sul; 2008.

16. Barbosa-Júnior A, Szwarcwald CL, Pascom A, Souza-Junior P. Tendências da epidemia de AIDS entre subgrupos sob maior risco no Brasil, 1980-2004. Cad Saúde Pública 2009; 25:727-37.

17. Bastide R, Fernandes F. Negros e brancos em São Paulo. São Paulo: Anhembi; 1955.

18. Maio MC. Tempo controverso: Gilberto Freyre e o projeto UNESCO. Tempo Social 1999; 2:111-36.

19. Guimarães ASA. Classes, raças e democracia. São Paulo: Editora 34; 2002.

Submitted on $11 / \mathrm{Jul} / 2011$

Approved on 04/Aug/2011 